\title{
LIDERANCGA: DIFICULDADES E POTENCIALIDADES DE UM LÍDER INTROVERTIDO NAS ORGANIZAÇÕES
}

\section{LEADERSHIP: DIFFICULTIES AND POTENTIALS OF A INTROVERT LEADER IN ORGANIZATIONS}

Recebido: 16/12/2014 - Aprovado: 06/04/2015 - Publicado: 15/05/2015

Processo de Avaliação: Double Blind Review

\author{
Pedro Henrique Faria Carvalho da Costa ${ }^{1}$ \\ Especialista em Gestão de Negócios \\ Universidade Braz Cubas - UBC \\ phfcosta@gmail.com
}

\section{RESUMO}

O objetivo deste estudo visa demostrar através de pesquisas teóricas e bibliográficas as potencialidades e dificuldades encontradas no indivíduo introvertido. A liderança, sobretudo pode ser vista como uma grande sinfonia, tendo o líder como o maestro. O que vai determinar se a apresentação será boa ou não é a capacidade e/ou habilidade que o líder possui para influenciar seus liderados para agirem conforme a música. Liderar é uma das atribuições, sendo ela crucial dentro das organizações. Perante isso se pode considerar que as empresas buscam pessoas com um determinado estilo de liderança, considerando fatores como: a assertividade, as habilidades de oratória, a expressão corporal, assim como se posicionar a frente. Características estas marcantes no estilo extrovertido, contudo, neste trabalho, será tratado o estilo oposto, dominado pela introversão, reflexão, compreensão e senso do cooperativo. Os resultados mostram que a liderança introvertida é minoria ou quase inexpressiva nas organizações, onde através de estudos encontra-se uma plena capacidade deles para com a liderança de uma equipe, de um setor ou até mesmo de uma organização.

Palavras-chaves: Liderança; Introversão; Organização

\footnotetext{
${ }^{1}$ Autor para correspondência: Universidade Braz Cubas - Av. Francisco Rodrigues Filho, 1233 -Mogilar. Mogi das Cruzes - SP, Brasil. CEP: 08773-380
} 


\begin{abstract}
This study aims to demonstrate through theoretical and bibliographical potentials and difficulties encountered in introvert searches. Leadership, overcoat can be seen as a great symphony, having the leader as the maestro. What determines whether the presentation it is good or not is the ability and / or skill that the leader has to influence their subordinates to act to the music according. To lead is one of the most crucial tasks within organizations. Considering that, companies seek people with a particular style of leadership, taking into account factors such as assertiveness, public speaking skills and body language. These are common characteristics of the extroverted style, however, the paper will be about the opposite style, Known as by introversion, reflection, understanding and cooperative sense. The results show that introverted leadership is almost insignificant minority or in organizations where through studies is full with their ability to lead a team in one sector or even an organization.
\end{abstract}

Key Words: Leadership; Introversion; Organization.

\title{
1. INTRODUÇÃO
}

Partindo do pressuposto de Hunter (2004) para a liderança "é a habilidade de influenciar pessoas para trabalharem entusiasticamente visando atingir aos objetivos identificados como sendo para o bem comum". Através deste pensamento, vemos que existem formas diversificadas para a liderança dentro das organizações, e que antigos paradigmas baseados no poder se tornam cada vez menos usuais nas corporações e nos negócios.

Independentemente do estilo de liderar, seja ela na forma introvertida - menos comum nas empresas - ou extrovertida, percebe-se que o sucesso ou insucesso das organizações está relacionado diretamente na importância dada ao capital humano, ou seja, o quanto os líderes influenciam outros a realizarem suas tarefas entusiasticamente em prol de um objetivo comum.

Tangente aos objetivos propostos neste artigo, os mesmos se concentraram em analisar um gênero específico da liderança, pouco estudado e praticado no mundo corporativo. Logo, faz-se importante mensurar as dificuldades e potencialidades do líder introvertido nas organizações, assim como descrever um pouco sobre esse gênero introverso, porém muito promissor.

Como forma de justificar essa escolha, partiremos de uma atual visão sobre aos grandes problemas atrelados à administração contemporânea, é possível apontar falhas gerenciais, onde o líder não exerce sua função corretamente, seja por inexperiência, pelo comportamento que tem para com seus subordinados, com isso, geram-se relatos sobre os conflitos, casos de insubordinação, turnovers dentre outros fatores organizacionais que impactam diretamente nas receitas da empresa. Resumidamente, podemos dizer que temos um líder conservador liderando jovens da geração Y, e jovens líderes liberais, conduzindo pessoas de gerações antecessoras as suas, onde vemos como resultado os conflitos supracitados acima. 
O papel do líder, como pilar fundamental, é de extrema importância na relação de gerir pessoas, administrar conflitos e superar desafios. Um embate gerado hoje é referente à capacidade de uma pessoa introspectiva assumir um papel tão importante dentro das organizações, além de gerir e gerenciar um negócio.

Para atender a esta premissa, encontra-se a necessidade de desenvolver uma pesquisa que aborde as qualidades e as dificuldades deste líder, assim como as dos demais estilos, buscando fazer um cruzamento entre eles para obter um estudo de campo que demostre as potencialidades de cada um.

Uma pessoa introvertida, dificilmente consegue se destacar frente a uma pessoa extrovertida, segundo Zack (2011) a introversão é inata, e as preferências são observadas desde cedo. A mesma define que os introvertidos são reflexivos, concentrados e auto dependentes. Por conta destas características, os mesmos apresentam dificuldades em realizar networks com outras pessoas por conta deste medo.

\footnotetext{
O medo é uma emoção natural e fundamental para o ser humano, experimentada diante de um estímulo concreto de ameaça. Mas o tipo de medo que vamos tratar não é essa emoção que mostra que temos de nos proteger, mas sim, um estado permanente de insegurança. É o que chamamos de falso medo (Shinyashiki, 2009, p.15)
}

Como base nisso, quais seriam as diversas formas encontradas para a liderança onde o líder é introvertido? E Qual a importância dele para as organizações dentro de uma área atrelada à gestão de pessoas?

O indivíduo introvertido, com todas suas qualidades no campo reflexivo, de concentração e autossuficiência, pode ser um gestor e exercer papel de liderança, mesmo contendo dificuldades em fazer networkings com outras pessoas, exercendo sim, uma liderança emotiva e servidora.

Como resultado disso, encontramos diante das teorias da liderança encontra-se o perfil do líder introvertido, caracterizado por ser, Harmonioso, Perfeccionista, Planejador, Estável (Perfil S), Pensativo e Criativo, capaz de realizar um empowerment em sua organização, descentralizando poderes e otimizando setores.

\section{CONCEITOS DE ADMINISTRAÇÃO E LIDERANÇA}

As corporações ou organizações são formadas por pessoas, com sentimentos motivacionais racionais diferentes, sujeitos às forças do ambiente onde convivem diariamente. Elementos estes das quais geram a amplitude da motivação, os relacionamentos e a liderança que desencadeiam o comportamento humano no grupo onde ele se situa.

Com esse olhar clássico da administração científica de Taylor (Taylorismo), ou seja, pautado no ideal de que a qualidade permitiria que uma pessoa comandasse a outra, onde as massas eram inertes, e que aguardavam uma voz ativa, para a tomada do poder e o 
comando, sendo a autoridade de comando em virtude do cargo ou função que a pessoa executava.

Justificando este pensamento, vemos que a origem da palavra administração, segundo Chiavenato (2011), vem do latim ad (direção, tendência para) e minister (subordinação ou obediência) e significa aquele que realiza uma função sob o comando de outrem, isto é, aquele que presta serviço a outro.

Até o final da década de 50, início dos anos 60, e com a difusão do Taylorismo e do Fordismo, o papel do chefe passa a ser o de sentar na cadeira e exercer controles mecânicos, baseando-se nos conceitos do POCC (Planejar, organizar, controlar e corrigir), além de impor sua autoridade frente a seus subordinados.

A origem da palavra Liderança, segundo Mueller e Maya (2003), vem do termo etimológico da palavra liderar que vem da expressão inglesa to lead, cujo significado estabelece: conduzir, dirigir, guiar, comandar, persuadir, encaminhar, encabeçar, capitanear, atravessar'. Percebe-se, que o papel do líder, é o de ser o pilar fundamental, sendo de extrema importância na relação de gerir pessoas, administrar conflitos e superar desafios.

Cury (1995) destaca que, a liderança é o resultado de uma constelação de qualidade no qual uma pessoa possui, enquanto outros asseguram que o líder não precisa dispor de regras, e sim de bons métodos de análises das situações sociais dentro da qual deve agir, onde a solução aparece naturalmente de acordo com a análise do ambiente.

Ressalta-se que:

[...] em crise não há liderança partilhada, quando o barco está afundando o capitão não pode convocar uma reunião para ouvir as pessoas, tem que dar ordens. Esse é o segredo da Liderança partilhada: saber em que situações deve agir como chefe e em que situações atuar como parceiro". Para ele "a tarefa do líder é desenvolver outros líderes", pois toda empresa necessita deles, ainda que muitas negligenciem o seu desenvolvimento. (DRUCKER, 1996, p.162).

Para tanto, a liderança é vista como necessária em todos os tipos de organização humana, principalmente nas empresas. "Qualquer que seja a posição ou o nível que ocupe, o administrador alcança resultados através da efetiva cooperação dos subordinados." (CHIAVENATO, 2011, p.12).

Segundo Kotter (1997), um líder tem como principal atividade a produção de mudança, com sua ação pautada sobre três dimensões fundamentais:

- Estabelecer a direção estratégica da empresa;

- Comunicar essas metas aos recursos Humanos;

- Motivá-los para que sejam cumpridas.

Com o surgimento de novas teorias, vemos que o pensamento sofre alterações, passando a retratar a organização como resultado de um trabalho coletivo onde todos passam 
a contribuir intelectualmente. As mudanças passam pela nomenclatura dos cargos hierárquicos, onde chefes passam a ser chamados de líderes, e os operários a serem chamados de funcionários e futuramente de colaboradores conforme figura 1 abaixo.

Figura 01: Diferenças entre líder e Chefe

\begin{tabular}{|c|c|}
\hline Líder & Chefe (Formal) \\
\hline Liderança informal & Autoridade Formal \\
\hline Emerge do grupo & É colocado no cargo \\
\hline Surge da crença dos liderados & Comum acordo \\
\hline Produto de inúmeros fatores & Atributo Singular \\
\hline Inspira Confiança & Exerce o controle \\
\hline Visão de longo prazo & Visão de curto prazo \\
\hline É seguido por acreditarem nele & É obedecido pelo seu posto \\
\hline
\end{tabular}

Fonte: GP Concursos,2012.

A teoria clássica que data a partir dos anos 60, tem como imagem, o líder que agia com o poder, coagindo seus subordinados, que por medo de perderem seus empregos trabalhavam contra sua vontade. Com os novos ideais propostos pelas teorias das relações humanas, a liderança passou a ser exercida com base na autoridade.

Chiavenato relata que:

\begin{abstract}
A influência significa uma força psicológica, uma transação interpessoal na qual uma pessoa age de modo a modificar o comportamento de outra de modo intencional. A influência envolve conceitos como poder e autoridade, abrangendo maneiras pelas quais se provocam mudanças no comportamento das pessoas ou de grupos sociais. (2011, p.118).
\end{abstract}

Hunter (2004) vai de encontro com o pensamento de Chiavenato, ao dizer que a liderança "é a habilidade de influenciar pessoas para trabalharem entusiasticamente visando atingir aos objetivos identificados como sendo para o bem comum". Através deste ponto de vista, vemos que existem formas diversificadas dentro das organizações, e que antigos paradigmas baseados no poder se tornam cada vez menos usuais nas corporações e nos negócios. "O poder diz respeito à capacidade que A tem de influenciar o comportamento de B, de maneira que B aja de acordo com a vontade de A. (ROBBINS, 2005, p.302).

Completando este ideal proposto por Chiavenato e Robbins, Hunter (2004, p. 24) define: "Poder: É a faculdade de forçar ou coagir alguém a fazer sua vontade, por causa de sua posição ou força, mesmo que a pessoa preferisse não o fazer'. O mesmo indaga que autoridade é: "A habilidade de levar as pessoas a fazerem de boa vontade o que você quer por causa de sua influência pessoal. 


\section{TEORIA SOBRE ESTILOS DE LIDERANÇA}

Chiavenato (2011), indaga que a liderança estabelece um dos temas mais pesquisados e estudados nas últimas décadas, onde os autores humanistas classificaram estas teorias em três grupos como se pode perceber na figura 2, onde ilustra as mesmas.

Figura 02: As teorias sobre liderança
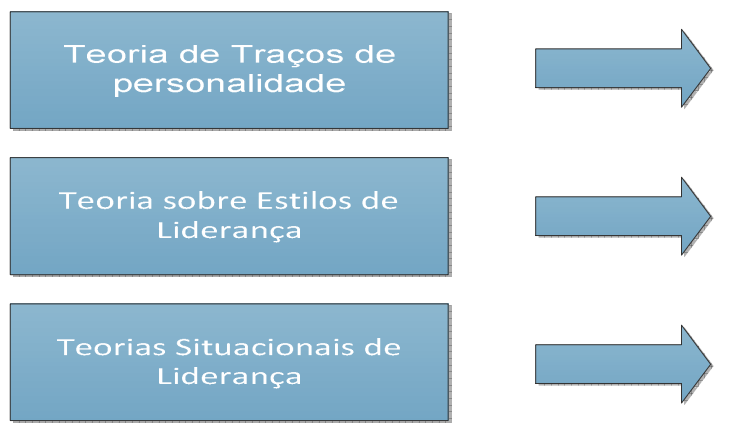

Fonte: CHIAVENATO, 2004, p.102.

Ferraz (2013) menciona os três tipos de líderes, sendo eles: O centralizador, que é aquele líder que retém todo poder em si, o segundo, o líder abdicador, aquele que delega todas as tarefas e só saberá o que aconteceu com elas quando deu certo ou errado. Por fim, temos o líder delegador, a qual ele delega funções e acompanha os resultados. Já para Metidieri (2011), existem várias teorias sobre os estilos de liderança, e em se tratando da visão de líder e liderado temos três estilos: O Autocrático, o Democrata e o Liberal.

Chiavenato (2011) ilustra bem essa visão pregada, pelos três estilos de liderança mais conhecidos são: Autocrático, Liberal e Democrático conforme demonstrado na figura 3, demostrando as diferentes ênfases aplicadas pelas três variações da liderança.

Figura 03: As diferentes ênfases decorrentes dos três estilos de liderança

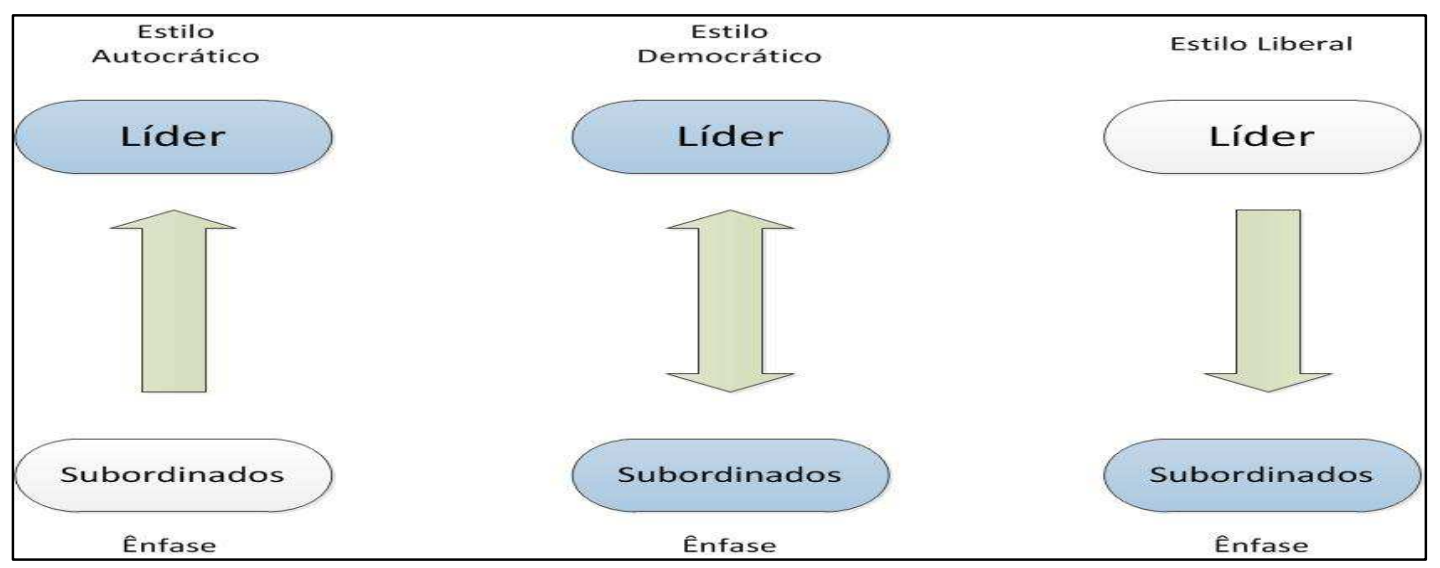


José Roberto Marques, presidente do Instituto Brasileiro de Coaching (IBC), traz um olhar diferenciado para estes três estilos, na qual o estilo autocrático é mantido, o democrático passa a ser chamado de participativo e o terceiro se mantém com a nomenclatura de liberal. Contudo, eles agregaram um quarto estilo, a da Liderança Coaching (Leader Coach), trazendo à tona a mais nova vertente da liderança.

Ladeia (2013) aponta um recente levantamento realizado pelo HayGroup, onde mostra os estilos de liderança ou gestão em 10 países, classificando-os percentualmente pelos seguintes tópicos: Coercitivo, Dirigente, Afetivo, Democrático, Modelador e Treinador conforme demostrado na tabela 1 abaixo.

Tabela 01: Estilos de Liderança

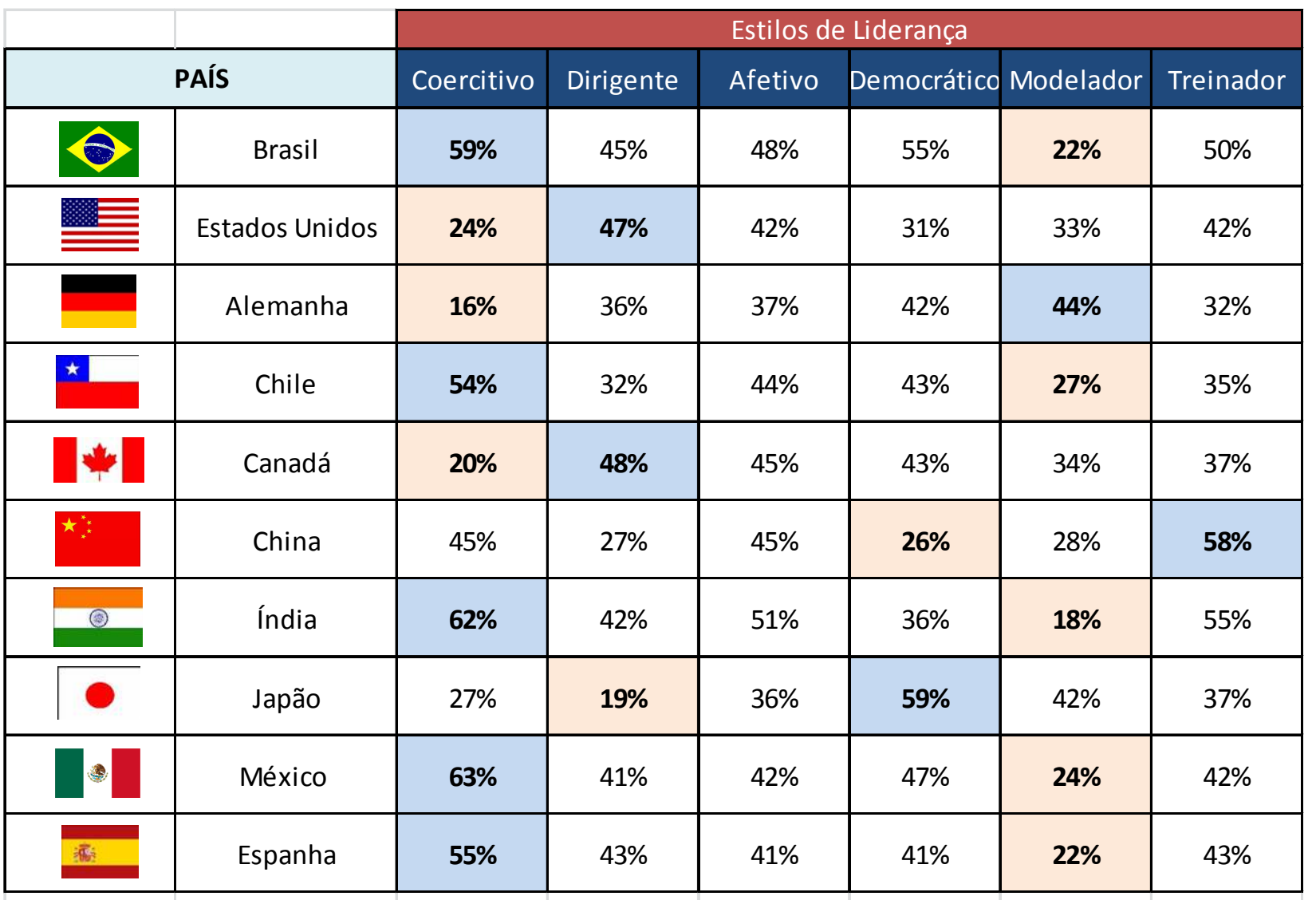

Habilidades de Liderança mais adotadas

Habilidades de Liderança menos adotadas

Fonte: LADEIA, 2013, modificado pelo autor. 
Analisando a tabela 01 acima, vemos que o estilo coercitivo é predominante em $50 \%$ dos países desta lista, sendo um deles o Brasil. Por outro lado, temos o estilo modelador como o menos usual entre os países.

Fazendo uma análise rápida sobre os estilos predominantes no Brasil, observa-se que dentre os países citados, ele detém médias muito próximas, demostrando que por mais que tenha a dominância do estilo coercitivo, há uma linha tênue entre os demais modelos, o que possa gerar certa instabilidade ou maior diferenciação nas empresas, sendo positivo ou negativo no espectro da liderança.

Cada tipo de comportamento está relacionado com o grau de autoridade utilizado pelo líder e o grau de liberdade disponível para os subordinados, dentro de um continuum de padrões de liderança.

Figura 04: Continuum de padrões de liderança

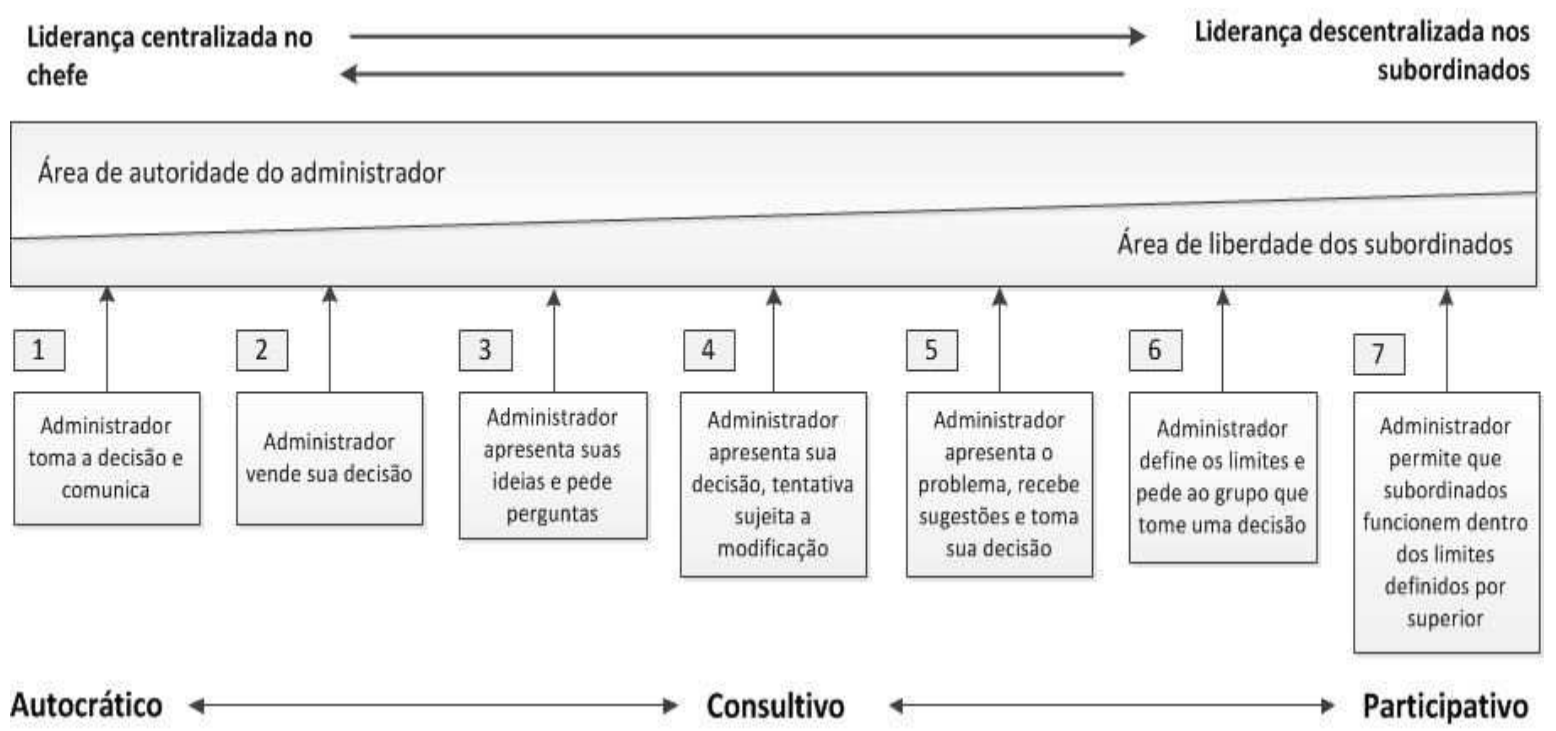

Fonte: CHIAVENATO (2011), p.122 modificado pelo autor.

O comportamento de liderança localizado no lado esquerdo denota o administrador que mantém alto grau de controle sobre os subordinados, enquanto o comportamento localizado no lado direito denota um administrador que permite ampla liberdade de ação aos subordinados, demonstrando os extremos entre o coercitivo e o liberal.

O Conselho Regional de Administração do Estado de São Paulo(2014), em uma pesquisa recente, fundamentada pela empresa de recrutamento Robert Half com cerca de 300 presidentes, superintendentes, diretores e gerentes de empresas de médio e grande porte do país, e identificaram que 9 entre 10 empresas (90\%) possuem perfis de liderança. Contudo, 64,2\% desses profissionais disseram que suas empresas não têm programas sistemáticos para identificar líderes. 
De acordo com a pesquisa, as três principais qualidades de um bom líder são inspirar outras pessoas (com 43,4\% das indicações), ter ética (42\%) e ser capaz de tomar decisões $(38,9 \%)$. Por outro lado, a pesquisa aponta o desequilíbrio emocional (26,4\%), a arrogância $(19,3 \%)$ e a centralização $(16,4 \%)$ como os maiores defeitos de um líder. (Conselho Regional de Administração do Estado de São Paulo, 2014).

Diante desses resultados, a pesquisa demonstra que $49,5 \%$ dos entrevistados relatam que o principal resultado prático de ter pessoas com essas qualidades e características de líderes na equipe é o aumento da produtividade, a melhoria do clima organizacional, a retenção de talentos. Nesse sentido, 73,2\% deles indagam o coaching como principal ferramenta para o desenvolvimento de novos líderes, além de oferecer desafios e integrar subordinados aos gestores.

O papel do líder, baseado nestes novos paradigmas, é fundamental para desenvolver e influenciar o clima organizacional, bem como motivar e melhorar o comprometimento dos funcionários, a confiança na empresa e a valorização do colaborador, gerando como resultado o respeito e a credibilidade. Vemos que estes fatores são de vital importância para que a empresa sobreviva em meio a tanta concorrência e desafios impostos por um universo globalizado.

Sotilli (2012, p.1) relata que:

Desempenho e bem estar, eram conceitos que até alguns anos atrás eram considerados antagônicos, no entanto, aos poucos, felizmente isso foi se modificando. As empresas se humanizaram, e passaram a dirigir os holofotes para o capital humano, assim que perceberam que são as pessoas que fazem à diferença e que esse capital não lhe pertence, apenas está à sua disposição, enquanto for capaz de gerenciá-lo de maneira eficaz.

Tonnera (2012, p.1) traz à tona o novo papel dos líderes, complementando a proposta de Sotilli no que tange o papel do líder, e afirma ao dizer que:

A capacidade de interação é essencial para um bom líder, é de vital importância
que ele seja visto e percebido como uma boa influência para sua equipe. À vontade
consiste na capacidade de alinhar intenções mais ações direcionadas a um foco
único. O amor devocional consiste na geração de alguns sentimentos, tais como:
Paciência, Gentileza, Humanidade, Respeito, Perdão, entre outros. Já a autoridade
é o uso da influência pessoal no sentido de direcionar indivíduos a aceitarem a sua
vontade.

Liderança é a interação entre pessoas que pode ser expressa pelo poder ou pela autoridade. Atualmente o olhar se baseia pela autoridade, com ênfase no lado humanitário, fazendo com que as organizações refletissem acerca do tema, buscando o líder ideal para ambas as partes, ou seja, quais características os funcionários queriam em seu gestor. 


\title{
4. A ESTRATÉGIA DOS INTROVERTIDOS
}

Apesar do equívoco comum de que pessoas introvertidas são tímidas, e vice versa, são fenômenos diferenciados. A Timidez ${ }^{2}$, segundo o Dicionário Aurélio, traz a mesma com fatores negativos atrelados a falta de coragem, insegurança, inibição e acanhamento.

"Timidez, aliás, que é tratada corriqueiramente como sinônimo de introversão, mas descreve, na verdade, uma característica bem diferente. A timidez está relacionada ao sofrimento pela exposição ao julgamento alheio e acomete principalmente aquelas pessoas que temem passar vergonha.' (MOROZINI, 2014, p.1).

Novamente o dicionário Aurélio, demostra um significado semelhante à timidez para a palavra Introvertido ${ }^{3}$, apontando por ele como um indivíduo absorto em si mesmo, voltado para dentro.

\begin{abstract}
A Introversão, por outro lado, caracteriza aqueles que preferem ficar sozinhos e se sentem mais produtivos no silêncio de seu isolamento. Quase todo tímido desenvolve um comportamento introvertido, mas o inverso não é necessariamente verdadeiro. (MOROZINI, 2014, p.1).
\end{abstract}

Percebe-se que a timidez é um sentimento atrelado a psicologia humana do indivíduo que não gosta de ficar "exposto" perante o julgamento de outras pessoas. Diante do exposto, o mesmo desencadeia um comportamento mais introvertido, ou defensivo, não se expondo a situações que ative esse sentimento.

A exposição exagerada desencadeia o medo, sendo ele presente em todas as pessoas - Introvertidas ou extrovertidas - e seres vivos do planeta. Essa defesa natural e instintiva faz com que ela se torne presente em nosso cotidiano. "A verdade é que o medo é um poderoso alicerce de decisões e está presente em praticamente todos os grandes acontecimentos do mundo. " (MELLO, 2013, p.38).

O medo é uma emoção natural e fundamental para o ser humano, experimentada diante de um estímulo concreto de ameaça. [...] não é essa emoção que mostra que temos de nos proteger, mas sim, um estado permanente de insegurança. É o que chamamos de falso medo. (SHINYASHIKI, 2009, p.15).

Para alguns, segundo Mello (2013, p. 40), o receito de falar em público, errar alguma etapa do projeto, levar críticas, pedir um aumento entre outras, vai de encontro com o desconhecido, criando barreiras e afirmações comuns como "eu não consigo" ou "eu não estou pronto" e, pode ser um alento para que as pessoas não busquem avançar.

\footnotetext{
${ }^{2}$ s.f Caráter de quem é tímido; falta de coragem. / Insegurança; acanhamento; inibição.

${ }^{3}$ adj. E s.m Voltado para dentro. / Absorto, introverso; absorto em si mesmo: caráter introvertido. (Antônimo.: Extrovertido).
} 
Com esse cenário, é muito comum que os profissionais passem a ter dúvidas sobre a sua identidade profissional e seus próprios interesses naquela organização. $\mathrm{O}$ contrário também é válido. [...] Complementando este cenário, as pessoas passaram a fazer o trabalho que antes era feito por duas, ou às vezes, até três pessoas. [...] Toda essa pressão pode gerar diversos medos nos profissionais como: medo de tirar férias, de liderar equipes, medo de opinar, medo de ser demitido, entre outros. (LIMAS, 2008, p.1).

Figura 05: Os maiores medos dos profissionais

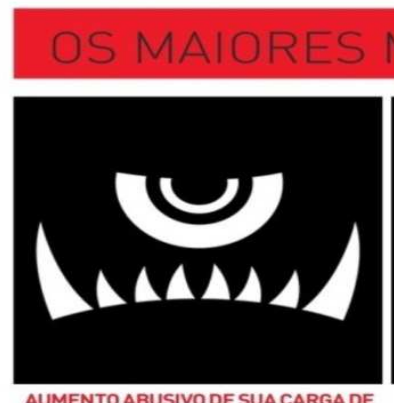

AUMENTO ABUSIVO DESUACARGA DE TRABALHO

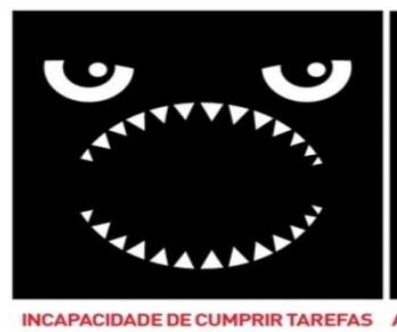
DE TRABALHO

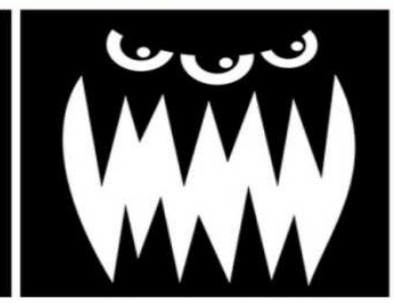

AMEACAASEPUNIC̣ŌES

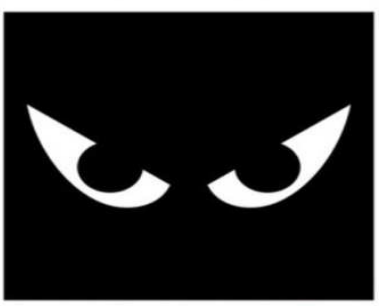

AMBIENTES DE TRABALHO INSTÁVEISE INSEGUROS

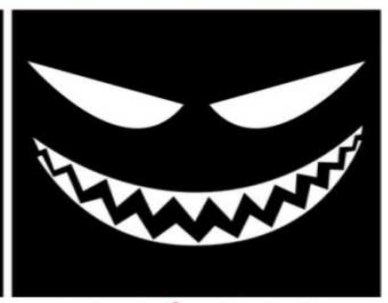

CONCORRENNCIA DESLEAL

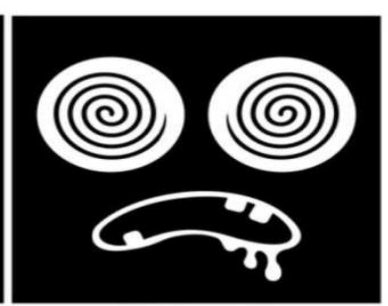

DESEMPREGO

Fonte: MELLO, 2013

Diante deste cenário, podemos compreender que a falta de confiança, a ausência da fé, a presença do falso medo, além da baixa autoconfiança, leva o colaborador de muitas empresas a não conseguirem se auto realizarem, gerando um ou mais aspectos negativos sobre as pessoas, o local de trabalho e até mesmo modificando sua personalidade.

Na teoria sobre a hierarquia das necessidades humanas, Maslow ${ }^{4}$ propôs uma pirâmide para demostrar o quão importante é o grau motivacional das pessoas para as organizações. Este comportamento chegou a ser objetivo de estudo de Frederick W. Taylor, pai da Administração científica, contudo, Maslow trouxe um olhar que traz como elemento chave a motivação Humana.

\footnotetext{
${ }^{4}$ Abraham H. Maslow (1908 - 1970), um dos maiores especialistas em motivação humana.
} 
Figura 06: Pirâmide Hierárquica das necessidades humanas - Maslow

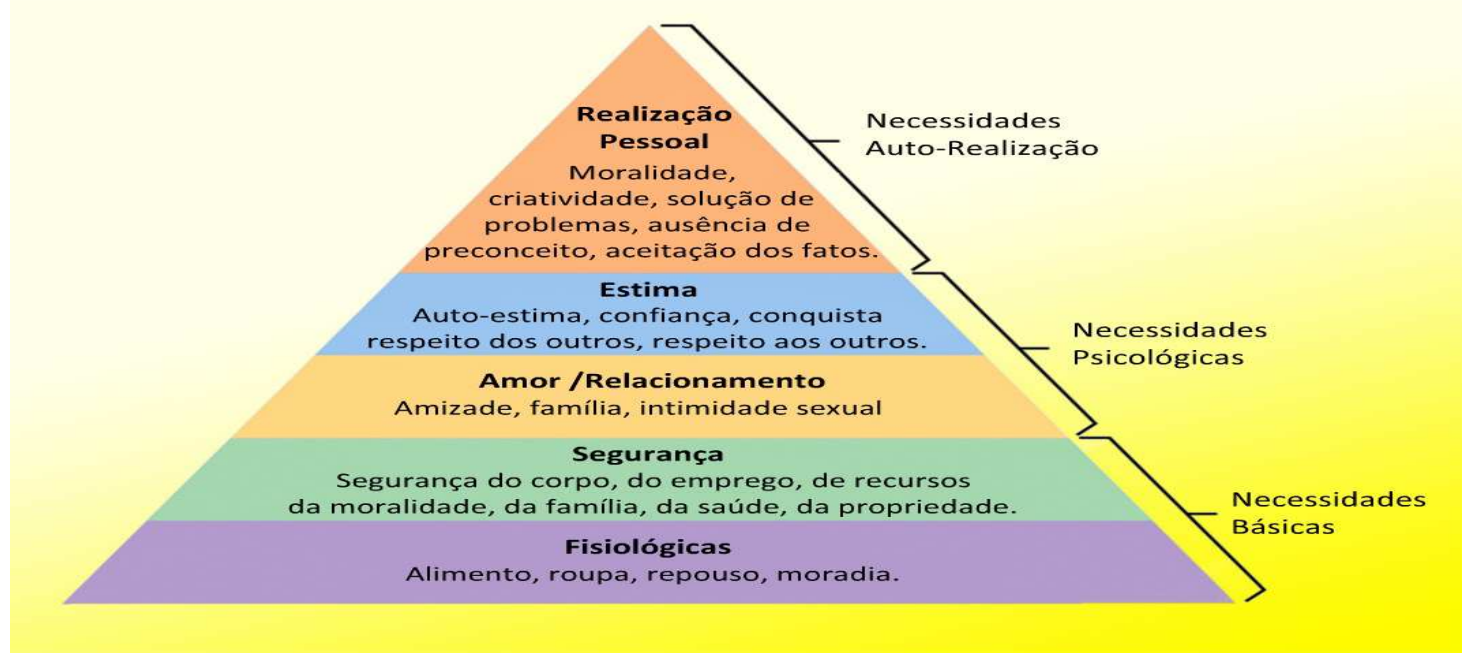

Fonte: Psicosmica, 2013

Na base da pirâmide, encontram-se os dois níveis relacionados às necessidades básicas do indivíduo (Fisiológicas e segurança), proposto como pilares de sustentação para que uma pessoa sobreviva em condições normais, como higiene, alimento, repouso, além de aspectos atrelados a segurança, tais como: à proteção contra alguns perigos, alguns aspectos ligados à estabilidade, em suma, tudo que traga certo conforto além do básico.

Avançando para a mediana dessa pirâmide, chegamos ao ponto chave que leva uma pessoa a se auto realizar ou perecer diante de uma situação que lhe traga sentimentos atrelados ao medo de progredir. Neste ponto, encontramos o que Roberto Shinyashiki caracteriza como o "triângulo da confiança".

\section{Figura 07: Triângulo da confiança}

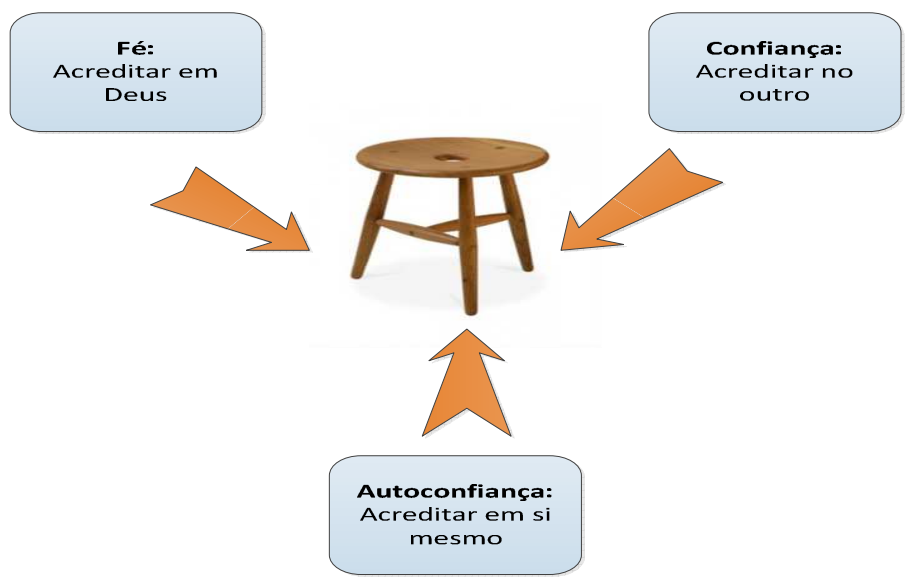


Fonte: SHINYASHIKI,2009, p. 39 modificado pelo autor.

Percebe-se, que neste setor intermediário, as necessidades envolvidas estão ligadas ao campo dos aspectos das patologias psicológicas, podendo ser elas positivas ou negativas.

Maslow e Shinyashiki concordam ao dizer que para adentrar no campo da satisfação, ou seja, aquele que se auto realiza (topo da pirâmide), é necessário que a pessoa busque em si, nas pessoas e até mesmo na religião algo que faça superar estes níveis, agregando novas amizades, novas conquistas, respeito e confiança.

A satisfação desse segmento faz com que a pessoa atinja o ápice da pirâmide, se auto realizando em todos os campos atrelados ao sucesso profissional, pessoal e moral. A não satisfação do mesmo tem como fator a negatividade, as frustações, fazendo com que sentimentos descritos venham novamente à tona.

\section{Figura 08: A satisfação e a não satisfação (frustação) das necessidades humanas básicas}

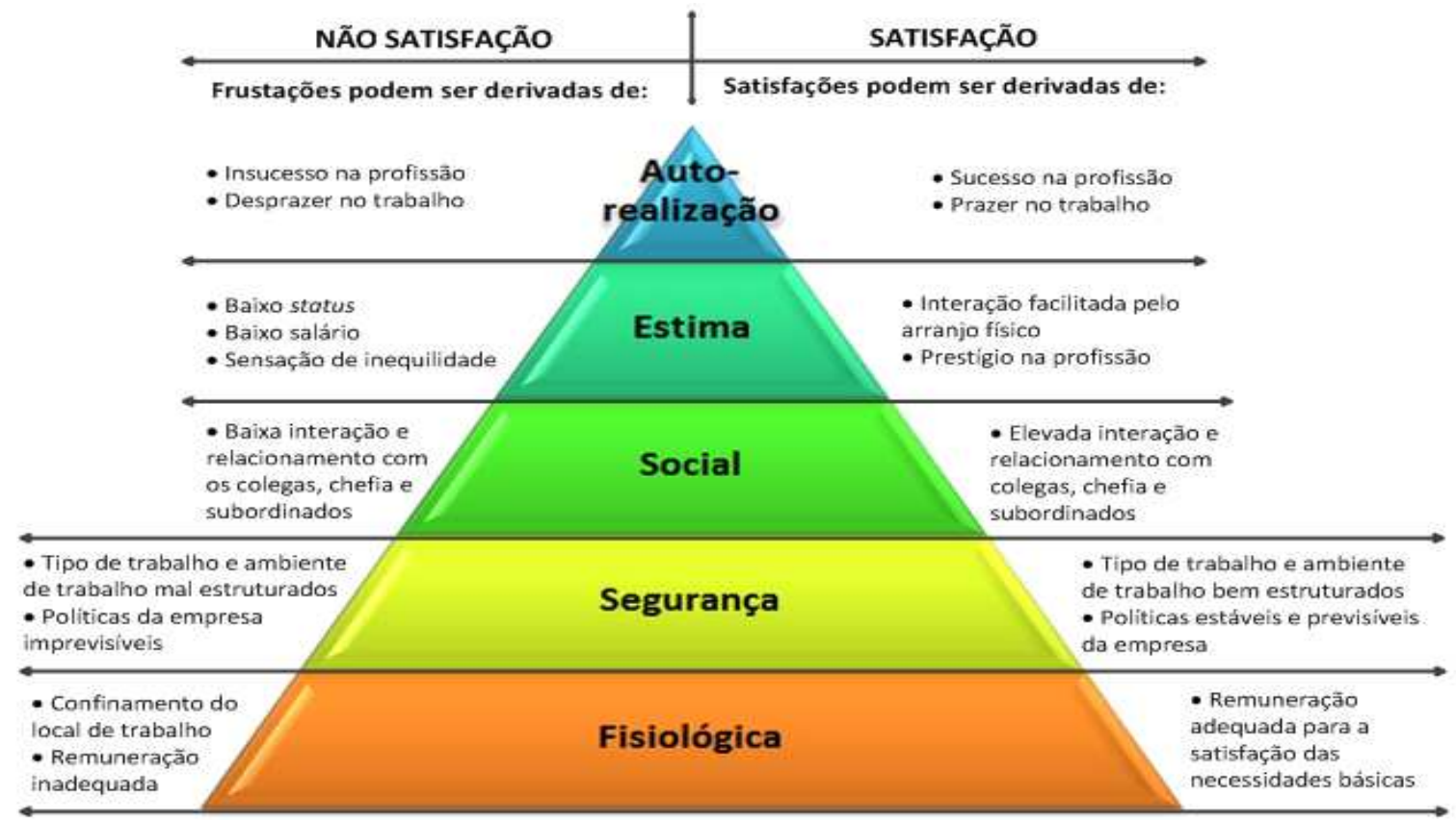

Fonte: CHIAVENATO,2011, p. 310 modificado pelo autor.

Na figura 08 acima, vemos que do lado esquerdo da pirâmide se concentra a não satisfação, encontrada normalmente nos colaboradores. Em contrapartida, no lado oposto, vemos indicadores motivacionais, que atendem a necessidade básica do funcionário. 
Todavia, em diferentes fases deste profissional, o mesmo irá se deparar com fatores atrelados a não satisfação, assim como indicadores de satisfação.

\section{DIFICULDADES E POTENCIALIDADES DA LIDERANÇA INTROVERTIDA}

As potencialidades deste perfil são marcadas pelo lado humanístico, valorizando as pessoas acima de qualquer coisa. Por conta desta virtude, são ótimos ouvintes, dominam como ninguém a habilidade de se manter calmo, equilibrado e tranquilo em momentos de estresse, sabendo planejar suas ações para tomar iniciativa no momento certo.

Por terem um círculo de amizade menor, são fiéis as pessoas e demostram ser de confiança tanto para a empresa quanto para o líder e/ou pessoas próximas. São persistentes na realização de suas tarefas, procurando se superar a todo e qualquer momento, sendo prestativo para atender as necessidades da empresa, da liderança e de seus amigos, demonstrando através de seu lado organizado e dedicado que são ótimos para cargos de confiança da empresa.

A estabilidade, tanto em suas ações, em sua vida como no emprego são marcantes, demonstrando novamente seu lado confiável, persistente, organizado e sociável para os objetivos propostos a ele, trabalhando sempre em prol da cooperação.

Com base nestas qualidades, são notáveis as atitudes que este indivíduo demonstra, sendo ele um ser pensativo, criativo e intuitivo ao realizar todos os seus atos, sendo metaforicamente águias. Apesar de possuir estas qualidades como suas potencialidades, este gênero é marcado também por suas dificuldades, que devem ser encaradas como pontos de melhoria e não de mudança.

Um contrassenso destoa neste perfil que por lado é harmonioso, mas costuma mesmo que sem intenção - ser arrogante com pessoas que não se encaixam com seu perfil, ficando estressados, principalmente quando as coisas não acontecem conforme o planejado, sendo rebeldes e radicais em seus pensamentos.

Em virtude disto, em muitas das vezes, o pensar no futuro e na maneira de antecipálo, ocorre um desequilíbrio em sua vida pessoal e no trabalho, ao mesmo tempo em que demoram a agir e a dar resultados.

Quando seu planejamento é afetado, costumam-se desanimar ficando ainda mais introvertido e reflexivo. Fica claro que por suas medidas controladas, procuram evitar ao máximo as mudanças e inovações.

Mas afinal, existem líderes introvertidos no mundo? Segundo Susan Cain (2012), autora do Best-Seller "O poder dos Quietos" relata que: "O que Albert Einstein, Barack Obama, Chopin, Steven Spielberg, J.K Rowling, Larry Page e Bill Gates têm em comum? A resposta é o sucesso. E a introversão." Nessa relação de nomes, encontramos um físico que desvendou mistérios acerca da teoria da relatividade, o presidente dos EUA, sendo ela uma potência mundial, um pianista, uma escritora de best-seller, um diretor de cinema premiado, o atual presidente do maior mecanismo de busca da internet (Google) e o CEO da Microsoft. 
Essas pessoas são aquelas que gostam de escutar a falar, ler a ir a festas e grandes eventos, inovam e criam, mas não gostam da autopromoção e preferem trabalhar por conta própria, mais do que em grupo.

Muitos psicólogos também concordam que introvertidos e extrovertidos trabalham de forma diferente. Extrovertidos tendem a terminar tarefas rapidamente. Eles tomam decisões rápidas (e às vezes drásticas) e sentem-se confortáveis com muitas tarefas ao mesmo tempo e ao correr riscos. Gostam da "excitação da caça" por recompensas como dinheiro e status.Introvertidos muitas vezes trabalham de forma lenta e ponderada. Eles gostam e se focar em uma tarefa de cada vez e podem ter um grande poder de concentração. São relativamente imunes às tentações da fama e fortuna. (CAIN, 2012, p.11)

Indivíduos com essa natureza conseguem sim exercer um papel importante na sociedade, nas empresas, conduzindo pessoas para um objetivo, mas, contudo, vale frisar que os exemplos famosos citados são de pessoas introvertidas que buscaram evoluir suas qualidades e seus pontos de melhoria, superando certas inseguranças.

Afinal, o que os recursos humanos têm a ver com a introversão, liderança introvertida? A resposta para essa questão é simples e clara, tudo! Dentro de uma organização, por mais tecnológica que seja a mesma é conduzida por pessoas, e essas pessoas conduzem outras, fomentando o principal ideal da liderança (Conduzir pessoas a realizarem uma determinada tarefa).

E a introversão? Aonde ela se encaixa? Para essa resposta, percebe-se que existem muitas lacunas a serem preenchidas, desde as fases primárias de recrutamento e seleção, até fases de preparo, treinamento e desenvolvimento de pessoas, principalmente das introvertidas.

\footnotetext{
Na condição de mentor na área de liderança, é tarefa sua avaliar de que maneira as pessoas sob sua orientação lidam com os relacionamentos. Algumas delas terão dificuldades para interagir com os colegas. Se detectar essa dificuldade em qualquer ponto na hierarquia da organização, procure treiná-las nessa área e ajudalas a interagir. (MAXWELL, 2011, p. 24)
}

"Vale lembrar que nem sempre um introvertido é tímido, já que a timidez pode chegar a ser uma fobia social, o medo da reprovação dos outros, evitando assim o contato com pessoas. E ainda, não existe um introvertido ou extrovertido puro [...]" (FREITAS, 2013, p.1).

Um estilo completa o outro, sendo pares, assim como a masculinidade e a feminilidade, os dois andam juntos. $\mathrm{O}$ vemos é uma curva de possibilidades que tendência um dos lados dependendo do perfil individual das pessoas, e as mesmas devem ser respeitadas e valorizadas. 


\section{CONSIDERAÇÕES FINAIS}

Os líderes são responsáveis pelas organizações, sendo eles encarregados de todos os processos (Administrativo, financeiro, produtivo, etc.) da empresa, desde a forma de planejar, ou seja, como tudo será realizado até a execução, tornando este processo o papel do gestor.

A liderança por si só não é algo que vem sobre uma bagagem genética, onde existem aqueles que nascem líderes e aqueles que nascem para serem liderados. Ela é pautada na base do poder e da autoridade, pela qual todos podem e exercerem papéis de liderança ao longo de sua vida, seja ela realizando trabalhos, planejando uma viagem, delegando funções, entre outras aptidões.

Um ponto a se destacar é que encontramos dois tipos de líderes, o introvertido e o extrovertido. O que diferencia um para outro, são suas personalidades, pela qual o extrovertido se sobressai por ser mais autoconfiante que o seu inverso, introvertido. Porém, o introvertido possui características que posicionam o mesmo como um excelente líder, por conta de sua preocupação com as pessoas e com as tarefas, deixando de lado os networkings desnecessários para outro momento.

Com base nestas informações obtidas teoricamente e conceitualmente, passamos a compreender como agem os gestores, mas não fundamenta a prática deles. Contudo, ao se realizar os testes comportamentais, e por mais que os mesmos possuem um embasamento teórico forte, é possível afirmar que aquela pessoa exposta ao teste, realmente age ou agirá como tal.

$\mathrm{Na}$ introversão, encontramos um perfil harmonioso, perfeccionista, planejador, estável, pensativo, criativo para o estilo de liderar, sendo caracterizado como servidores, fazedores e realizadores, o que resulta no modelo introvertido de liderar.

Com isso, conclui-se, que os objetivos presentes neste trabalho foram alcançados, demonstrando os estilos de liderança, a introversão humana assim como as qualidades e potencialidades do líder introvertido nas organizações. Contudo, este é apenas um estudo preliminar, na qual o mesmo deve ser aprofundado a fim de obterem-se maiores respostas.

\section{REFERÊNCIAS}

CAIN, Susan. O poder dos quietos: como os tímidos e introvertidos podem mudar o mundo que não para de falar. Tradução Ana Carolina Bento Ribeiro. Rio de Janeiro: Agir, 2012.

CHIAVENATO, Idalberto. Comportamento organizacional: a dinâmica do sucesso das organizações. São Paulo: Thomson, 2004.

Janeiro: Elsevier, 2011.

Introdução a Teoria Geral da Administração - $8^{a}$ ed. - Rio de 
CONSELHO REGIONAL DE ADMINISTRAÇÃO DO ESTADO DE SÃO PAULO. Centro do conhecimento: Perfis de liderança estão em $90 \%$ das empresas brasileiras, diz pesquisa. São Paulo, 2012. Disponível em: <http://www.crasp.gov.br/crasp/WebForms/ interna.aspx ?campo=2382> Acesso em: 23/08/2014.

CURY, Antonio. Organização e métodos: uma visão holística. 6. ed. . São Paulo: Atlas, 1995.

DRUCKER, Peter Ferdinand. Administrando para o futuro: os anos 90 e a virada do século. Tradução de Nivaldo Montigelli Júnior. São Paulo: Pioneira, 1996.

EXAME.COM. Disponível em: <http://exame.abril.com.br/videos/dicas-paraempreendedores/os-3-principais-tipos-de-lideres> Acesso em: 2 set.2013.

FERREIRA, Aurélio Buarque de Holanda. Dicionário Aurélio Básico da Língua Portuguesa. Rio de Janeiro: Nova Fronteira, 1999.

FREITAS, Lívia. Introvertidos, é hora de mostrar seus poderes. Vagas. 07 out. 2013. Disponível em: <http://www.vagas.com.br/profissoes/acontece/no-mercado/introvertido/>. Acesso em: 23 out 2014

HUNTER, James C. O monge e o executivo: uma história sobre a essência da liderança. Rio de janeiro: Sextante, 2004.

KOTTER, John P. Liderando mudança. Tradução de LeadingChange. Rio de Janeiro: Campus, 1997.

LADEIA, Bárbara. Conheça os estilos de gestão em 10 países. Exame.com. 20 jun. 2013. Disponível em: <http://exame.abril.com.br/gestao/noticias/os-estilos-de-gestao-em-10paises\# 2>. Acesso em Acesso em 20 nov. 2013

LÍDER X CHEFE. GP concursos. 13 out 2012. Disponível em: <http://gpparaconcursos. blogspot.com.br/2012/10/lider-X-chefe.html>. Acesso em 20 nov. 2013

LIMAS, Daniel. Os medos dos profissionais. Catho. 28 nov. 2008. Disponível em: <http:// www.catho.com.br/carreira-sucesso/sem-categoria/os-medos-dos-profissionais>. Acesso em: 20 nov. 2013.

MAXWELL, John C. O livro de ouro da liderança. $2^{a}$ ed. Rio de janeiro: Thomas Nelson Brasil, 2011.

MELlO, Fábio B. de. 2013/21: sob o domínio do medo. Administradores, João Pessoa, v.21, p. 36-41, jun/jul. 2013

METIDIERI, Guilherme. Estilos de liderança: Autocrática, democrática e liberal. Administradores, 3 de março de 2011. Disponível em: <http://www.administradores.com.br /artigos/administracao-e-negocios/estilos-de-lideranca-autocratica-democratica-e-liberal/ 52800/> Acesso em: 2 set.2013. 
MOROZINI, Adriano. A cultura da extroversão. Administradores. 17 jan. 2014. Disponível em: <http://administradores.com.br/mobile/artigos/carreira/a-cultura-daextroversao/75113/>. Acesso em: 18 jan. 2014

MUELLER, Adriana; MAYER, Léia. Liderança: Novos conceitos diante de uma nova realidade. VI SEMEAD, 8, 2003, Santa Catarina.

PSICOSMICA. Psicologia Humanista. Psicosmica. 2013. Disponível em: <http://www.psicosmica.com/2012/06/psicologia-humanista.html>. Acesso em 10 jan. 2014.

ROBBINS, Stephen P. Comportamento organizacional. Tradução técnica de Reynaldo Marcondes. - 11. ed. - São Paulo: Person Prentice Hall, 2005.

SHINYASHIKI, Roberto. A coragem de confiar: O medo é o seu pior inimigo. São Paulo: Editora Gente, 2009.

SOTILLI, Patrícia. O papel do líder na empresa, algumas funções básicas. Administradores. 19 set. 2012. Disponível em: <http://www.administradores.com.br/ artigos/marketing/o-papel-do-lider-na-empresa-algumas-funcoes-basicas/66035/>. Acesso em 20 nov. 2013

TONNERA, Anderson. O novo papel dos líderes dentro das organizações. Administradores. 16 set. 2012. Disponível em: <http://www.administradores.com.br/ artigos/administracao-e-negocios/o-novo-papel-dos-lideres-dentro-dasorganizacoes/65969/>. Acesso em: 20 out 2013.

ZACK, Devora. Coisas que odeio em networking: Um guia prático para quem não tem paciência de fazer social ou é autêntico demais. São Paulo: Saraiva, 2011. 